\title{
Accuracy and Prognostic Role of NCCT-ASPECTS Depend on Time from Acute Stroke Symptom-onset for both Human and Machine-learning Based Evaluation
}

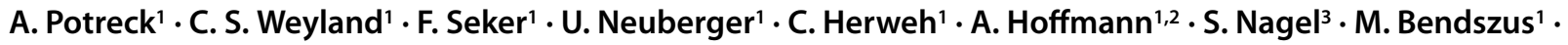 \\ M. A. Mutke ${ }^{1}$
}

Received: 28 June 2021 / Accepted: 4 October 2021 / Published online: 28 October 2021

(c) The Author(s) 2021, corrected publication 2022

\begin{abstract}
Purpose We hypothesize that the detectability of early ischemic changes on non-contrast computed tomography (NCCT) is limited in hyperacute stroke for both human and machine-learning based evaluation. In short onset-time-to-imaging (OTI), the CT angiography collateral status may identify fast stroke progressors better than early ischemic changes quantified by ASPECTS.

Methods In this retrospective, monocenter study, CT angiography collaterals (Tan score) and ASPECTS on acute and follow-up NCCT were evaluated by two raters. Additionally, a machine-learning algorithm evaluated the ASPECTS scale on the NCCT (e-ASPECTS). In this study 136 patients from 03/2015 to 12/2019 with occlusion of the main segment of the middle cerebral artery, with a defined symptom-onset-time and successful mechanical thrombectomy (MT) (modified treatment in cerebral infarction score $\mathrm{mTICI}=2 \mathrm{c}$ or 3 ) were evaluated.

Results Agreement between acute and follow-up ASPECTS were found to depend on OTI for both human (Intraclass correlation coefficient, ICC $=0.43$ for OTI $<100 \mathrm{~min}, \mathrm{ICC}=0.57$ for OTI $100-200 \mathrm{~min}, \mathrm{ICC}=0.81$ for OTI $\geq 200 \mathrm{~min}$ ) and machine-learning based ASPECTS evaluation $(\mathrm{ICC}=0.24$ for OTI $<100 \mathrm{~min}, \mathrm{ICC}=0.61$ for OTI $100-200 \mathrm{~min}, \mathrm{ICC}=0.63$ for OTI $\geq 200 \mathrm{~min}$ ). The same applied to the interrater reliability. Collaterals were predictors of a favorable clinical outcome especially in hyperacute stroke with OTI $<100 \mathrm{~min}$ (collaterals: $\mathrm{OR}=5.67 \mathrm{CI}=2.38-17.8, p<0.001$; ASPECTS: OR=1.44, $\mathrm{CI}=0.91-2.65, p=0.15)$ while ASPECTS was in prolonged OTI $\geq 200 \mathrm{~min}$ (collaterals $\mathrm{OR}=4.21, \mathrm{CI}=1.36-21.9, p=0.03$; ASPECTS: $\mathrm{OR}=2.85, \mathrm{CI}=1.46-7.46, p=0.01)$.

Conclusion The accuracy and reliability of NCCT-ASPECTS are time dependent for both human and machine-learning based evaluation, indicating reduced detectability of fast stroke progressors by NCCT. In hyperacute stroke, collateral status from CT-angiography may help for a better prognosis on clinical outcome and explain the occurrence of futile recanalization.
\end{abstract}

Keywords Stroke $\cdot$ Brain $\cdot$ Computed tomography $\cdot$ CT angiography $\cdot$ Thrombectomy

M. A. Mutke

Matthias.Mutke@med.uni-heidelberg.de

1 Department of Neuroradiology, Heidelberg University Hospital, Heidelberg, Germany

2 Institute of Diagnostic and Interventional Neuroradiology, Inselspital Bern University Hospital, Bern, Switzerland

3 Department of Neurology, Heidelberg University Hospital, Heidelberg, Germany

$\begin{array}{ll}\begin{array}{ll}\text { Abbreviations } \\ \text { ASPECTS }\end{array} & \begin{array}{l}\text { Alberta Stroke Program Early Computed } \\ \text { Tomography Score }\end{array} \\ \text { CTA } & \text { CT angiography } \\ \text { ICC } & \text { Intraclass-correlation coefficient } \\ \text { MT } & \text { Mechanical thrombectomy } \\ \text { NCCT } & \text { Non-contrast computed tomography } \\ \text { NIHSS } & \text { National Institutes of Health Stroke Scale } \\ \text { OTI } & \text { Onset-time to imaging } \\ \text { OTT } & \text { Onset-time to treatment }\end{array}$




\section{Introduction}

Mechanical thrombectomy (MT) is a successful and effective treatment in acute ischemic stroke due to large vesselocclusion $[1,2]$. While treatment decision in extended time from symptom onset to treatment (OTT) relies on defined mismatch criteria $[3,4]$, patient selection in OTT $\leq 6 \mathrm{~h}$ relies typically on the extent of early signs of infarction on non-contrast CT (NCCT) [5]. To quantify these, the Alberta Stroke Program Early Computed Tomography Score (ASPECTS) was established [6].

Still, futile recanalization occurs and, in a small proportion of patients, follow-up imaging after successful recanalization reveals larger infarction than expected from pretreatment imaging. Especially in hyperacute stroke, ischemic changes on acute NCCT can be very subtle [7-9]. So, reduced interrater-reliability was observed for ASPECTS within an onset-time to imaging (OTI) $\leq 100 \mathrm{~min}$ [10]. In patients treated with intravenous alteplase, a significant timeto-CT interaction regarding interrater-reliability and prognostic accuracy of ASPECTS has been reported before [11].

We therefore examined the time-dependent reliability and accuracy of ASPECTS by analyzing ASPECTS on acute and follow-up NCCT in patients with complete mechanical recanalization. In this collective, treatment effect is homogeneous and secondary infarct growth is expected to be minimal. We suppose that NCCT-ASPECTS more accurately represents final infarct extent in longer OTI, while it may not identify fast stroke progressors in short OTI. This should apply to both human, observer-dependent ASPECTS reading and observer-independent machine-learning based ASPECTS evaluations. Secondly, collateral supply on CTangiography has been proven to be a major predictor of final infarct size and clinical outcome before [12-14]. We propose that the collateral status may fill the diagnostic gap from NCCT-ASPECTS in hyperacute stroke and may help to explain futile recanalization.

\section{Material and Methods}

\section{Patient Characteristics}

The study was approved by the local ethics board. In this retrospective, monocenter study, we included 265 consecutive stroke patients between 03/2015 and 12/2019 with occlusion of the main segment of the middle cerebral artery (MCA) with a known, defined symptom onset time who underwent $\mathrm{CT}$ imaging prior and 1 day after MT at our institution. Further inclusion criterion was complete or near complete MT (modified thrombolysis in cerebral infarction score $=2 \mathrm{c}$ or 3$)$. This was achieved in $141(53 \%)$ patients and 5 patients were further excluded ( 2 patients due to large space occupying hemorrhagic transformation on follow-up imaging and 3 patients due to severe motion artifacts on NCCT). In total, 136 patients were included in the analysis. Baseline patient characteristics are displayed in supplemental Table 1. Median OTI was $139 \mathrm{~min}$ (IQR $81-203 \mathrm{~min}$ ), median time from imaging to flow restoration was $86 \mathrm{~min}$ (IQR 62-119 min). Favorable clinical outcome 3 months after stroke was defined as modified Rankin scale score $(\mathrm{mRS}) \leq 2$ or $\mathrm{mRS}=3$ in patients with pre-stroke $\mathrm{mRS}=3$. Information on mRS was available in 128 (94\%) patients.

\section{CT Imaging}

Imaging was carried out on a 64-slice CT scanner (Somatom Definition AS, Siemens Healthineers, Erlangen, Germany). NCCT was acquired at $120 \mathrm{kV}$ with automated adjustment of the tube current. Images were reconstructed by iterative image reconstruction (SAFIRE, Siemens Healthineers) with a kernel of J31 and a slice thickness (ST) of 1 and $4 \mathrm{~mm}$ for all patients examined later than 10/2016 (92 of 136 patients, 68\%). For the remaining, only images with a ST of $4 \mathrm{~mm}$ reconstructed by filtered-back-projection (kernel of H41) were available. Acquisition parameters for single-phase CT-angiography were $120 \mathrm{kV}$ at $20 \mathrm{~mA}$ after intravenous administration of a single bolus of $65 \mathrm{~mL}$ iodine contrast agent (Xenetix 350, Guerbet, Villepinte, France) followed by a $20 \mathrm{~mL}$ saline flush at a flow rate of $4 \mathrm{~mL} / \mathrm{s}$.

\section{ASPECTS Scoring and Evaluation of Collateral Status}

ASPECTS were rated on acute and follow-up NCCT by two experienced radiologists (MM and AP, more than 5 years of experience in stroke imaging), blinded to all other imaging and clinical data except for hemispheric stroke lateralization. Additionally, acute ASPECTS was evaluated by machine-learning based e-ASPECTS Software (e-Stroke Suite Version 9.0, Brainomix Ltd, Oxford, United Kingdom). When available, e-ASPECTS was evaluated on images with $1 \mathrm{~mm}$ ST. In cases where e-ASPECTS indicated ischemic changes in the unaffected hemisphere, e-ASPECTS was set to 10 . A consensus rating by $\mathrm{MM}$ and AP was introduced for the acute and follow-up ASPECTS.

Collateral status was evaluated on CT angiography by a third radiologist $(\mathrm{CW}$, more than 3 years of experience in acute stroke imaging) blinded to all other imaging using the Tan score [15]. In patients who received CT angiography externally before transfer to our hospital, collateral status was evaluated on externally acquired images. Subgroup analysis was carried out with respect to internal or external CT angiography. 


\section{Statistical Analysis}

Statistical analysis was performed with R (The R Project for Statistical Computing, V3.1.2). Interrater-reliability and agreement of acute and follow-up ASPECTS were assessed by two-way random effects, absolute agreement intraclass correlation coefficients $(\operatorname{ICC}(2,1))$. Group differences were assessed by Wilcoxon-rank sum test and Kruskal-Wallis test, correlations with Spearman rank-correlation analysis. Univariate and multivariate logistic regressions were carried out for neurological outcome at 3 months. Significance level was set to $\alpha=0.05$. Medians are given with their interquartile range (IQR), means with their standard deviation, all confidence intervals (CI) are quoted as $95 \%$ CI.

\section{Results}

\section{Time-dependent Interrater-reliability of ASPECT Soring}

We defined three subgroups based on OTI: a) hyperacute stroke with OTI $<100 \min$ (55 patients, $40 \%$ ); b) imaging between 100 and $200 \mathrm{~min}$ (45 patients, 33\%) and c) imaging $\geq 200$ min after symptom onset (36 patients, $27 \%$ ).

Interrater reliability was assessed by intraclass correlation coefficient separately between the two raters A and B, as well as separately between the e-ASPECTS and the consensus rating and, lastly, for all raters together (rater A, B and e-ASPECTS). Over all raters, lowest interrater reliability was found for the hyperacute setting with $\mathrm{ICC}=0.54$ (CI $0.39-0.68$ ), compared to ICC $=0.74$ (CI $0.61-0.83$ ) for OTI in between $100-199 \mathrm{~min}$ and $\mathrm{ICC}=0.79$ (CI 0.66-0.88) for patients with OTI $\geq 200 \mathrm{~min}$ (Table 1).

Noticeably, agreement between the consensus rating and the e-ASPECTS was highest for OTI of 100-199 min $(\mathrm{ICC}=0.88 \quad(0.79-0.93)$. In the latest time window (OTI $>200 \mathrm{~min}$ ), agreement between e-ASPECTS and the consensus rating was higher in patients without prior contrast agent administration (20/36 patients, $\mathrm{ICC}=0.82$ $(0.58-0.92)$ compared to ICC $=0.74(0.40-0.89)$ in patients
Table 1 Interrater reliability of the acute ASPECTS (Alberta Stroke Program Early Computed Tomography Score) according to the time from symptom onset to imaging. For both human and machinelearning based ASPECTS evaluation, interrater-reliability is found to be lowest in the hyperacute setting with OTI(onset-time to imaging) $<100 \mathrm{~min}$. For the two human raters, it was highest in OTI $\geq 200 \mathrm{~min}$, whereas agreement between the human consensus rating and the e-ASPECTS was highest for OTI of 100-199 min. (ICC intraclass correlation coefficient, $C I$ confidence interval)

\begin{tabular}{llll}
\hline & & \multicolumn{2}{l}{ Interrater reliability between } \\
\cline { 3 - 4 } & & Rater A and B & $\begin{array}{l}\text { Consensus rating and } \\
\text { e-ASPECTS }\end{array}$ \\
\hline OTI (min) & $N$ & ICC $(\mathrm{CI})$ & ICC $(\mathrm{CI})$ \\
$0-99$ & 55 & $0.72(0.57-0.83)$ & $0.57(0.36-0.72)$ \\
$100-199$ & 45 & $0.78(0.64-0.88)$ & $0.88(0.79-0.93)$ \\
$\geq 200$ & 36 & $0.91(0.83-0.95)$ & $0.78(0.59-0.88)$ \\
Overall & 136 & $0.79(0.72-0.85)$ & $0.75(0.67-0.82)$ \\
\hline
\end{tabular}

with prior contrast agent administration and secondary transfer to our hospital). There were no relevant differences regarding prior contrast administration for the two raters or other time windows. Moreover, there was no significant difference in OTI between the two CT reconstruction groups ( $p=0.06)$, nor did human ratings $(p=0.15)$ or e-ASPECTS $(p=0.5)$ differ significantly between these two groups.

\section{Time-dependent Accuracy of ASPECT Scoring}

Median ASPECTS was $9(7-10)$ on acute NCCT and 8 (6-9) on follow-up imaging $(p<0.001)$. On a subgroup level, difference between acute and follow-up ASPECTS was evident only in the subgroup with $\mathrm{OTI} \leq 100 \mathrm{~min}$ $(p<0.001)$, see Table 1 . Correspondingly, agreement between acute and follow-up ASPECTS improved considerably with longer OTI across all ratings (individual, consensus and e-ASPECTS, see Table 2). These results did not depend on prior, external contrast-agent administration (supplemental Table 2).

Patients who presented with short OTI had a larger decrease in ASPECTS from acute to follow-up imaging than patients with longer OTI. Importantly, this effect was not confined to the group analysis. Instead, OTI corre-

Table 2 Agreement between acute and follow-up ASPECTS (Alberta Stroke Program Early Computed Tomography Score) according to the time from symptom onset time to imaging (OTI). Agreement is only moderate in short onset-time to imaging and improves substantially in the later time windows. These findings apply to both human and machine-learning based ASPECTS (e-ASPECTS) evaluation

\begin{tabular}{lllllll}
\hline OTI & Acute & Follow-up & Rater A & Rater B & Consensus-rating & e-ASPECTS \\
& ASPECTS & ASPECTS & & & & ICC (CI) \\
\hline Min & Median (IQR) & Median (IQR) & ICC (CI) & ICC (CI) & ICC (CI) & $0.24(0.04-0.49)$ \\
$0-99$ & $9(8-10)$ & $7(6-9)^{\text {a }}$ & $0.47(0.06-0.71)$ & $0.42(0.05-0.66)$ & $0.43(0.02-0.68)$ & $0.67(0.27-0.76)$ \\
$100-199$ & $8(7-10)$ & $8(6-9)$ & $0.46(0.15-0.67)$ & $0.48(0.17-0.69)$ & $0.57-0.78)$ \\
$\geq 200$ & $8(7-10)$ & $8(7-9)$ & $0.83(0.67-0.92)$ & $0.77(0.57-0.88)$ & $0.81(0.60-0.91)$ & $0.63(0.22-0.82)$ \\
Overall & $9(7-10)$ & $8(6-9)^{\text {a }}$ & $0.51(0.24-0.69)$ & $0.49(0.22-0.66)$ & $0.52(0.22-0.70)$ & $0.42(0.15-0.61)$ \\
\hline
\end{tabular}

${ }^{a}$ Indicates significant differences 

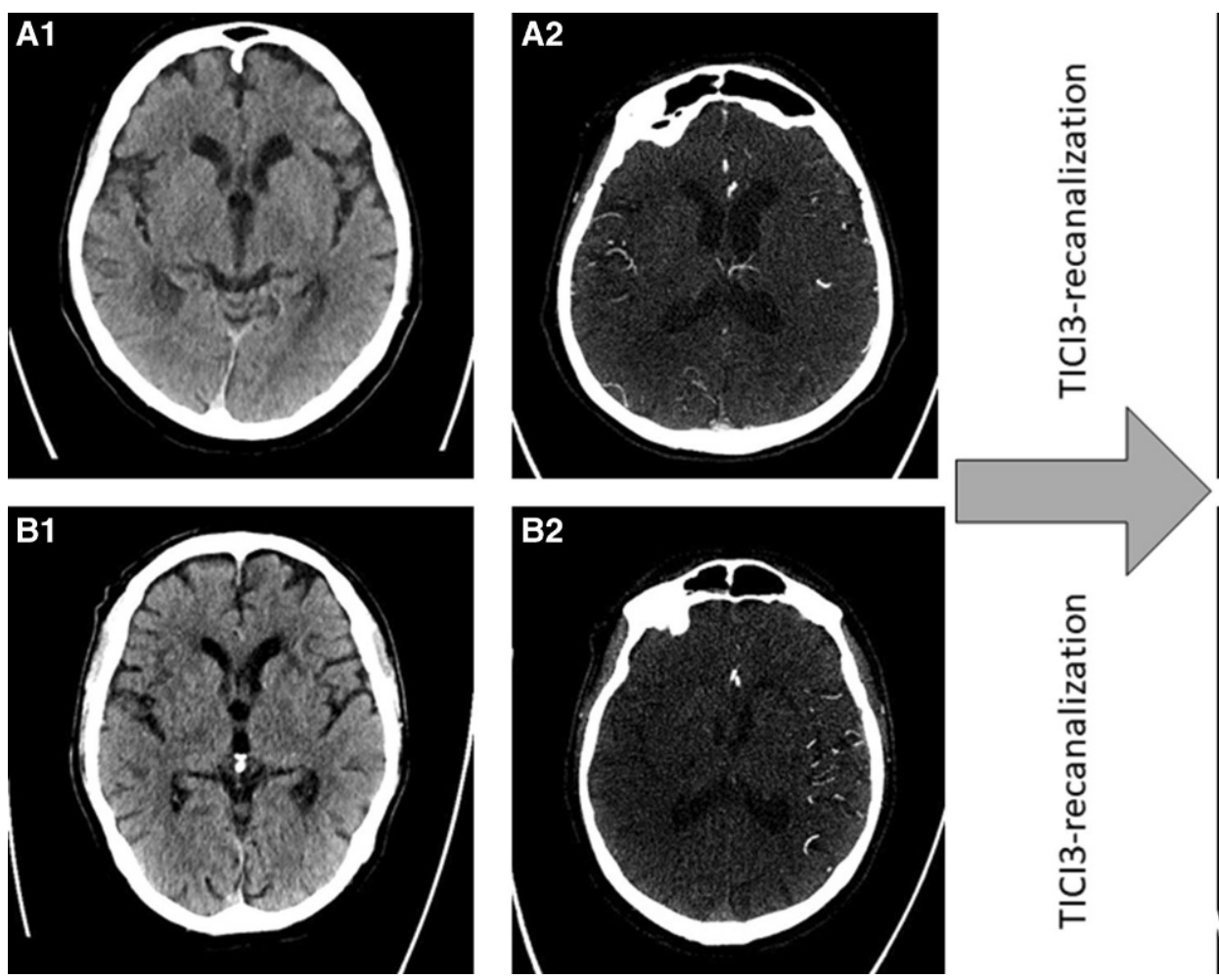

Fig. 1 Acute and follow-up imaging of two exemplary patients (A and B) who both underwent acute CT imaging within less than 100 min after symptom onset and who both underwent complete recanalization (mTICI3) of their right-sided middle cerebral artery M1 segment occlusion (patient A within $30 \mathrm{~min}$, patient B within 39 min after image acquisition). On acute NCCT $(\mathrm{A} 1+\mathrm{B} 1)$, early ischemic changes were found for both patients along the right insular ribbon. However, patient A had excellent collateral supply on CT-angiography (A2), while patient B had no collateral filling (B2). On follow-up imaging, large infarction is observed in patient B (B3), while ischemic changes are still confined to the insular ribbon in patient $\mathrm{A}(\mathrm{A} 3)$

lated directly with the difference (or shift) between acute and follow-up ASPECTS $(\rho=-0.28, \mathrm{CI}=-0.43-0.13)$, $p<0.001$ for rater $\mathrm{A}, \rho=-0.23(\mathrm{CI}=-0.38-0.07), p=0.008$ for rater $\mathrm{B}, \rho=-0.22(\mathrm{CI}=-0.38-0.06), \quad p=0.01$ for e-ASPECTS and $\rho=-0.33(\mathrm{CI}=-0.47-0.19), p<0.001$ for the consensus rating.

We also noted more decrease (or negative shift) between acute and follow-up ASPECTS as time from imaging to recanalization increased $(\rho=0.20(0.04-0.37), p=0.02$ for the consensus rating and $\rho=0.20(0.03-0.37), p=0.02$ for the e-ASPECTS rating). No further significant correlations between decrease in ASPECTS and time from imaging to recanalization were found on a subgroup level.

\section{Collateral Status and OTI}

CT angiography was acquired simultaneously with NCCT in 104 patients $(76 \%)$, whereas 32 patients $(24 \%)$ underwent external CT angiography and secondary transfer to our hospital. In one patient externally acquired CT angiography was not available for collateral scoring.

Overall median Tan score was 2 (1-3). Thereby, Tan score was 1 (1-2) in the subgroup with OTI $<100 \mathrm{~min}$, whereas median Tan score was $3(2-3)$ in the latest time window with OTI $\geq 200 \mathrm{~min}(p=0.01)$. Spearman correlation analysis was significant between Tan scores and ASPECTS $(p=0.003$ for the consensus rating, $p=0.01$ for the e-ASPECTS and $p<0.001$ for follow-up ASPECTS), see also exemplary patients in Fig. 1. On a subgroup level, correlation was significant only in the early subgroup with $\mathrm{OTI}<100 \mathrm{~min}$ ( $p=0.001$ for the consensus rating, $p=0.003$ for the e-ASPECTS and $p<0.001$ for the followup ASPECTS) and not in the later time windows. This was independent of external or in-house CT angiography acquisition (Table 3 and supplemental table 3 ).

\section{Clinical-outcome Analysis}

A favorable clinical outcome 3 months after stroke was observed in 83 of 128 patients $(65 \%)$. In the univariate analysis, significant predictors of a favorable clinical outcome were ASPECTS (consensus rating: OR: 1.87 (1.44-2.52), $p<0.001$, e-ASPECTS: OR 1.77 (1.38-2.34), $p<0.001)$, Tan score (OR: $2.00(1.37-2.94), p<0.001)$ and NIHSS at admission (OR: $0.86(0.80-0.92), p<0.001)$. In our cohort, OTI was not a significant predictor, nor 
Table 3 Collateral status (Tan score) as a function of OTI (onset-time to image). Significant correlation between Tan score and ASPECTS (Alberta Stroke Program Early Computed Tomography Score) was found especially in the short OTI

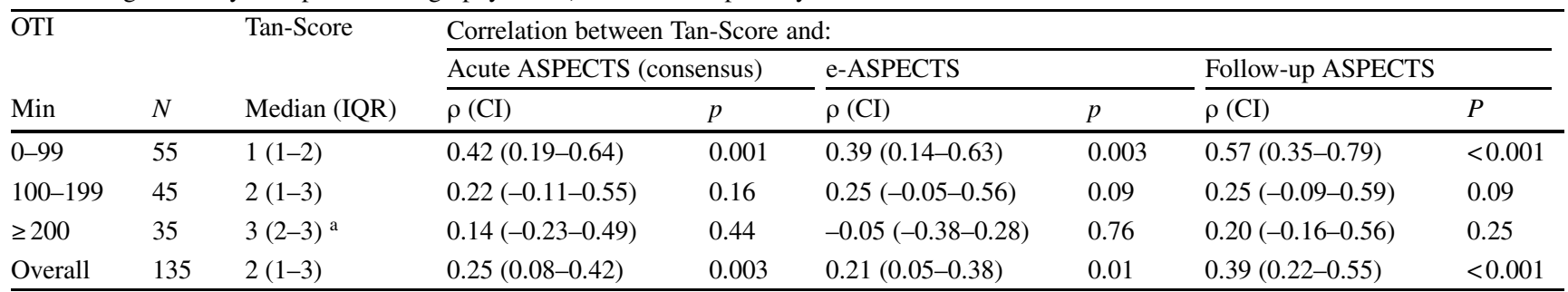

${ }^{a}$ A selection bias towards patients with better collaterals in the later time windows is noted $(p=0.01)$

Table 4 Multivariate logistic regression analysis including either observer-dependent ASPECTS or machine-learning based e-ASPECTS and collaterals (Tan score) as predictors of a favorable clinical outcome 3 months after stroke. Predictive roles dependent on OTI with collaterals being a significant predictor especially in hyperacute stroke with $\mathrm{OTI}<100 \mathrm{~min}$ compared to ASPECTS is in the later time windows

\begin{tabular}{|c|c|c|c|c|c|c|c|c|}
\hline \multirow[t]{2}{*}{$\overline{\mathrm{OTI}}$} & \multicolumn{2}{|l|}{ All patients } & \multicolumn{2}{|l|}{$\mathrm{OTI}<100 \mathrm{~min}$} & \multicolumn{2}{|c|}{ OTI $\geq 100-199 \mathrm{~min}$} & \multicolumn{2}{|l|}{ OTI $\geq 200 \mathrm{~min}$} \\
\hline & $\mathrm{OR}(\mathrm{CI})$ & $p$-value & $\mathrm{OR}(\mathrm{CI})$ & $p$-value & $\overline{\mathrm{OR}(\mathrm{CI})}$ & $p$-value & $\overline{\mathrm{OR}(\mathrm{CI})}$ & $\overline{p \text {-value }}$ \\
\hline \multicolumn{9}{|c|}{ User-dependent rating: } \\
\hline $\begin{array}{l}\text { ASPECTS (con- } \\
\text { sensus rating) }\end{array}$ & $1.79(1.38-2.44)$ & $<0.001$ & $1.46(0.91-2.65)$ & 0.15 & $1.34(0.86-2.24)$ & 0.2 & $2.85(1.46-7.46)$ & 0.01 \\
\hline $\begin{array}{l}\text { Collaterals (Tan } \\
\text { score) }\end{array}$ & $1.82(1.22-2.84)$ & 0.004 & $5.67(2.38-17.8)$ & $<0.001$ & $4.04(1.76-12.3)$ & 0.004 & $4.21(1.36-21.9)$ & 0.03 \\
\hline \multicolumn{9}{|c|}{ Machine-learning based ASPECTS evaluation: } \\
\hline e-ASPECTS & $1.69(1.31-2.26)$ & $<0.001$ & $1.28(0.72-2.39)$ & 0.4 & $1.43(0.97-2.28)$ & 0.09 & $3.43(1.66-9.47)$ & 0.004 \\
\hline $\begin{array}{l}\text { Collaterals (Tan } \\
\text { score) }\end{array}$ & $1.83(1.22-2.79)$ & 0.004 & $6.00(2.52-18.7)$ & $<0.001$ & $3.85(1.63-11.8)$ & 0.006 & $4.03(1.36-20.6)$ & 0.03 \\
\hline
\end{tabular}
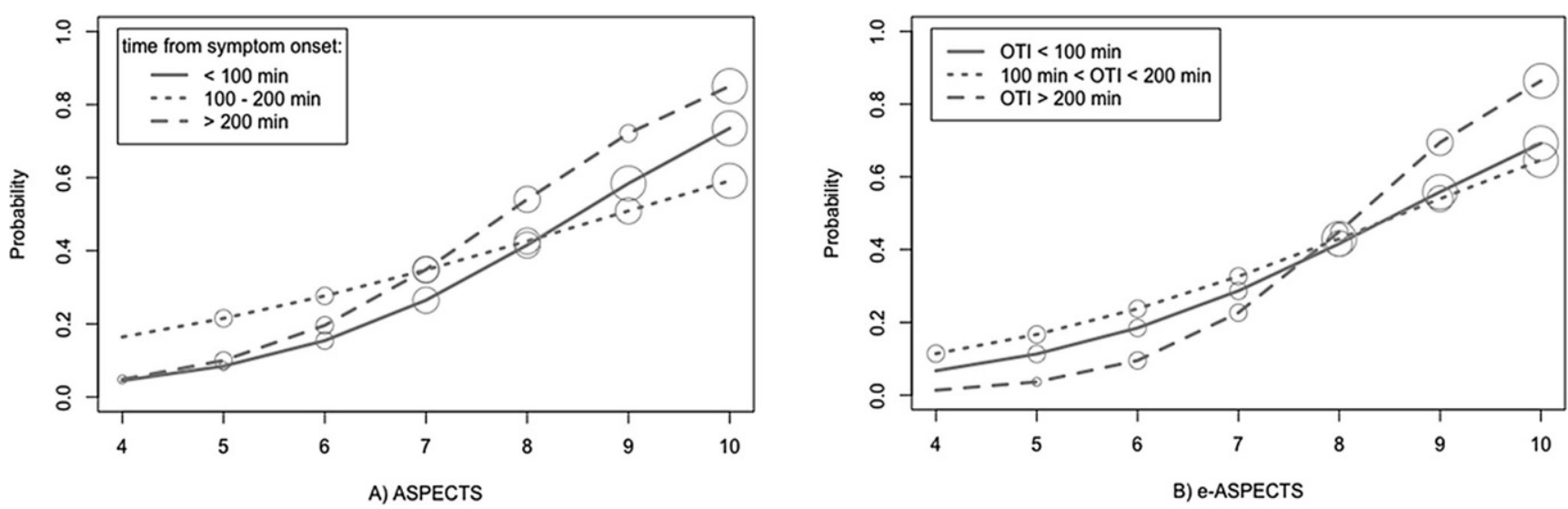

$$
\circ N=1 \quad \begin{aligned}
& \text { Number of Observations: } \\
& O N=2-5 \quad \mathrm{~N}=6-10 \bigcirc \mathrm{N}>10
\end{aligned}
$$

Fig. 2 Results of univariate logistic regression analysis: Probability of a favorable clinical outcome 3 months after stroke as a function of a observer-dependent ASPECTS and $\mathbf{b}$ machine-learning based e-ASPECTS. In patients who presented more than 200 min after symptom onset, ASPECTS was a better predictor of clinical outcome than in earlier time windows for both ASPECTS and e-ASPECTS

was time from symptom onset to recanalization (OR 1.00 (1.00-1.01), $p>0.5$ for both). Also, administration of intravenous thrombolysis (OR $0.84(0.39-1.76), p>0.5)$, age (OR $0.97(0.93-1.00), p=0.1)$ or sex (OR $1.14(0.55-2.37)$, $p>0.5$ ) were not significant predictors in our study population. Multivariate analysis including acute ASPECTS, Tan score and NIHSS at admission revealed significant predic- tion of a favorable clinical outcome for all three (ASPECTS OR: $1.67(1.26-2.32), p<0.001$ or e-ASPECTS OR: 1.60 $(1.23-2.16), p=0.001)$, Tan score OR: $1.64(1.05-2.59)$, $p=0.03$, NIHSS OR: $0.90(0.83-0.97), p=0.006$.

To additionally analyze the time-dependent prognostic roles of NCCT and collaterals, univariate and multivariate logistic regression analysis for a favorable clinical outcome 
were conducted for the three time-dependent subgroups including ASPECTS and (for multivariate analysis) Tan score. Thereby, pre-interventional ASPECTS was found to be a significant predictor especially in $\mathrm{OTI} \geq 200 \mathrm{~min}$, whereas Tan score was also in hyperacute stroke with OTI $<100 \mathrm{~min}$. These findings apply for human observerdependent ASPECTS and the e-ASPECTS (see Table 4 and Fig. 2).

\section{Discussion}

We demonstrate that the reliability and accuracy of NCCTASPECTS depend on the time from symptom onset to imaging. Interrater-reliability and agreement between acute and follow-up ASPECTS is found to be reduced in short OTI for both human and machine-learning based ASPECTS evaluation.

A particular strength of this study is the focus on patients who underwent complete mechanical recanalization. Previous works studied the time-dependent accuracy and prognostic value of ASPECTS only in patients treated with intravenous thrombolysis $[10,11,16]$. Compared to these studies, the treatment effect is more homogeneous in our study and the time-dependent accuracy of ASPECTS can be assessed more precisely. We found that patients who underwent imaging within a short OTI exhibited more frequently larger infarcts on follow-up imaging than expected from acute imaging. The most likely explanation is that early ischemic changes on NCCT are only very subtle in patients who present in such short OTI [7-9, 17].

This thesis is further supported by the inclusion of the e-ASPECTS in our study. e-ASPECTS did not detect any subtle changes in hyperacute stroke which may be invisible to the human eye. While non-inferiority of e-ASPECTS was demonstrated before [18], this time-dependency of e-ASPECTS was not. As an interesting side effect of our analysis, we found that agreement between e-ASPECTS and the observer-dependent rating was highest in the medium time window with OTI of 100-199 min. One possible explanation could be that e-ASPECTS is trained most for this time window. Also, we noted a reduced agreement between human consensus rating and e-ASPECTS in patients with prior external contrast-agent administration. This was more frequent in the latest time window with OTI $>200 \mathrm{~min}$. In those patients, ischemiarelated blood-brain barrier disruptions may have led to contrast agent extravasation. Potentially, an enhanced tissue contrast and higher overall density values did then influence the e-ASPECTS.

Secondly, we investigated whether collateral status from CTA fills the diagnostic gap in hyperacute stroke. Thereby, we found that collateral status correlated with acute and fol- low-up ASPECTS and clinical outcome after recanalization especially in patients with $\mathrm{OTI}<100 \mathrm{~min}$. CTA collaterals allowed for a better prognosis in patients undergoing MT in hyperacute stroke and helped to explain the occurrence of futile mechanical recanalization.

We remark that a third integral part of acute stroke imaging is perfusion imaging. Such imaging is mandatory for patient selection in prolonged time-windows greater than $6 \mathrm{~h}[3,4]$ but current guidelines do not consider it essential for decision-making in shorter time windows [3]; however, the reduced detectability of infarcted tissue by NCCT in the hyperacute setting, as demonstrated in our study, raises the question on whether perfusion imaging may help to identify ischemic tissue especially in the earlier time windows. NCCT-ASPECTS had higher accuracy and reliability in the prolonged time windows for both human and machinelearning based evaluation. Still, in extended time windows, perfusion thresholds have to be met to justify treatment decisions [19]. While our study does not allow for a conclusive analysis on this topic, it strongly motivates for further research on whether NCCT-ASPECTS may be suited as a main selection criterion also in longer OTI. We point out that vice versa, one must not conclude from our study that CT perfusion may be needed in hyperacute stroke for patient selection. Instead, in patients who presented very early after symptom onset and in whom NCCT did not reveal extensive early ischemic changes, a priory probability for a favorable clinical outcome was high as well. For these patients, thrombectomy may be justified per se and regardless of possible infarct underestimation on NCCT. Acquisition of CT angiography is mandatory to diagnose large-vessel occlusion. By assessing the collateral status, we found that it does also allow for a prognosis on the clinical outcome and helps to explain the occurrence of futile recanalization. Conventional CT-perfusion protocols come at the cost of higher radiation dose and the need for more contrast agent. Moreover, CT perfusion may not allow to withhold patients from MT either, due to the risk of infarct overestimation in the hyperacute setting [20-23].

Our study has limitations: First, besides the detectability of early ischemic changes, also infarct growth within the time from imaging until flow restoration leads to a decrease in ASPECTS. Still, this effect was not confined to one of the time windows. Another limitation of our study results from our retrospective, monocentric study design. Compared to a prospective cohort of patients with strokelike symptoms, the reported accuracies of ASPECTS may be superior. Moreover, we observed a bias towards patients with better collateral status as OTI increased. Noteworthy, this bias occurred although patient selection for MT is not based on collateral status at our institution. Hence, patients with poor collateral supply who presented in a later time window were less likely to be found eligible to undergo MT, 
possibly due to an already large extent of early ischemic changes on NCCT. This may also explain why correlation between ASPECTS and collateral status was not found to be significant when regarding the extended time window. Further, reconstruction kernel or slice thickness could affect the accuracy of ASPECTS [24, 25] and could not be considered in our retrospective analysis.

\section{Conclusion}

In patients with acute occlusion of the MCA M1 segment who all underwent mechanical recanalization with successful reperfusion, we demonstrate that the accuracy of ASPECTS evaluation is time dependent for both human and observer-independent, machine-learning based evaluation. In ultrashort OTI, collaterals aided to explain the occurrence of futile recanalization. CT-angiography collateral status and NCCT-ASPECTS were complementary surrogate parameters of infarct evolution with different sensitivity regarding time from symptom onset to imaging.

Supplementary Information The online version of this article (https:// doi.org/10.1007/s00062-021-01110-5) contains supplementary material, which is available to authorized users.

Funding Open Access funding enabled and organized by Projekt DEAL.

\section{Declarations}

Conflict of interest A. Potreck, C.S. Weyland, F. Seker, U. Neuberger, C. Herweh, A. Hoffmann, S. Nagel, M. Bendszus and M.A. Mutke declare that they have no competing interests.

Ethical standards Institutional Review Board approval was obtained. Written informed consent was waived by the Institutional Review Board of the University of Heidelberg.

Open Access This article is licensed under a Creative Commons Attribution 4.0 International License, which permits use, sharing, adaptation, distribution and reproduction in any medium or format, as long as you give appropriate credit to the original author(s) and the source, provide a link to the Creative Commons licence, and indicate if changes were made. The images or other third party material in this article are included in the article's Creative Commons licence, unless indicated otherwise in a credit line to the material. If material is not included in the article's Creative Commons licence and your intended use is not permitted by statutory regulation or exceeds the permitted use, you will need to obtain permission directly from the copyright holder. To view a copy of this licence, visit http://creativecommons.org/licenses/by/4. $0 \%$.

\section{References}

1. Saver JL, Goyal M, van der Lugt A, Menon BK, Majoie CB, Dippel DW, Campbell BC, Nogueira RG, Demchuk AM, Tomasello A, Cardona P, Devlin TG, Frei DF, du Mesnil de Rochemont R,
Berkhemer OA, Jovin TG, Siddiqui AH, van Zwam WH, Davis SM, Castaño C, Sapkota BL, Fransen PS, Molina C, van Oostenbrugge RJ, Chamorro Á, Lingsma H, Silver FL, Donnan GA, Shuaib A, Brown S, Stouch B, Mitchell PJ, Davalos A, Roos YB, Hill MD; HERMES Collaborators. Time to Treatment With Endovascular Thrombectomy and Outcomes From Ischemic Stroke: A Meta-analysis. JAMA. 2016;316:1279-88.

2. Pfaff J, Rohde S, Engelhorn T, Doerfler A, Bendszus M, Möhlenbruch MA. Mechanical Thrombectomy Using the new Solitaire $^{\mathrm{TM}}$ Platinum Stent-retriever : Reperfusion Results, Complication Rates and Early Neurological Outcome. Clin Neuroradiol. 2019;29:311-9.

3. Albers GW, Marks MP, Kemp S, Christensen S, Tsai JP, OrtegaGutierrez S, McTaggart RA, Torbey MT, Kim-Tenser M, LeslieMazwi T, Sarraj A, Kasner SE, Ansari SA, Yeatts SD, Hamilton S, Mlynash M, Heit JJ, Zaharchuk G, Kim S, Carrozzella J, Palesch YY, Demchuk AM, Bammer R, Lavori PW, Broderick JP, Lansberg MG; DEFUSE 3 Investigators. Thrombectomy for Stroke at 6 to 16 Hours with Selection by Perfusion Imaging. N Engl J Med. 2018;378:708-18.

4. Nogueira RG, Jadhav AP, Haussen DC, Bonafe A, Budzik RF, Bhuva P, Yavagal DR, Ribo M, Cognard C, Hanel RA, Sila CA, Hassan AE, Millan M, Levy EI, Mitchell P, Chen M, English JD, Shah QA, Silver FL, Pereira VM, Mehta BP, Baxter BW, Abraham MG, Cardona P, Veznedaroglu E, Hellinger FR, Feng L, Kirmani JF, Lopes DK, Jankowitz BT, Frankel MR, Costalat V, Vora NA, Yoo AJ, Malik AM, Furlan AJ, Rubiera M, Aghaebrahim A, Olivot JM, Tekle WG, Shields R, Graves T, Lewis RJ, Smith WS, Liebeskind DS, Saver JL, Jovin TG; DAWN Trial Investigators. Thrombectomy 6 to 24 Hours after Stroke with a Mismatch between Deficit and Infarct. N Engl J Med. 2018;378:11-21.

5. Balami JS, Sutherland BA, Edmunds LD, Grunwald IQ, Neuhaus AA, Hadley G, Karbalai H, Metcalf KA, DeLuca GC, Buchan AM. A systematic review and meta-analysis of randomized controlled trials of endovascular thrombectomy compared with best medical treatment for acute ischemic stroke. Int J Stroke. 2015;10:1168-78. Erratum in: Int J Stroke. 2017;12:NP7.

6. Barber PA, Demchuk AM, Zhang J, Buchan AM. Validity and reliability of a quantitative computed tomography score in predicting outcome of hyperacute stroke before thrombolytic therapy. ASPECTS Study Group. Alberta Stroke Programme Early CT Score. Lancet. 2000;355:1670-4. Erratum in: Lancet 2000;355:2170.

7. Dzialowski I, Weber J, Doerfler A, Forsting M, von Kummer R. Brain tissue water uptake after middle cerebral artery occlusion assessed with CT. J Neuroimaging. 2004;14:42-8.

8. Mintorovitch J, Yang GY, Shimizu H, Kucharczyk J, Chan PH, Weinstein PR. Diffusion-weighted magnetic resonance imaging of acute focal cerebral ischemia: comparison of signal intensity with changes in brain water and $\mathrm{Na}+\mathrm{K}(+)$-ATPase activity. J Cereb Blood Flow Metab. 1994;14:332-6.

9. Hatashita S, Hoff JT, Salamat SM. Ischemic brain edema and the osmotic gradient between blood and brain. J Cereb Blood Flow Metab. 1988;8:552-9.

10. Bal S, Bhatia R, Menon BK, Shobha N, Puetz V, Dzialowski I, Modi J, Goyal M, Hill MD, Smith EE, Demchuk AM. Time dependence of reliability of noncontrast computed tomography in comparison to computed tomography angiography source image in acute ischemic stroke. Int J Stroke. 2015;10:55-60.

11. Naylor J, Churilov L, Chen Z, Koome M, Rane N, Campbell BCV. Reliability, Reproducibility and Prognostic Accuracy of the Alberta Stroke Program Early CT Score on CT Perfusion and Non-Contrast CT in Hyperacute Stroke. Cerebrovasc Dis. 2017;44:195-202.

12. Liebeskind DS. Collateral circulation. Stroke. 2003;34:2279-84.

13. Menon BK, Qazi E, Nambiar V, Foster LD, Yeatts SD, Liebeskind D, Jovin TG, Goyal M, Hill MD, Tomsick TA, Broderick JP, Demchuk AM; Interventional Management of Stroke III Inves- 
tigators. Differential Effect of Baseline Computed Tomographic Angiography Collaterals on Clinical Outcome in Patients Enrolled in the Interventional Management of Stroke III Trial. Stroke. 2015;46:1239-44.

14. Berkhemer OA, Jansen IG, Beumer D, Fransen PS, van den Berg LA, Yoo AJ, Lingsma HF, Sprengers ME, Jenniskens SF, Lycklama À Nijeholt GJ, van Walderveen MA, van den Berg R, Bot JC, Beenen LF, Boers AM, Slump CH, Roos YB, van Oostenbrugge RJ, Dippel DW, van der Lugt A, van Zwam WH, Marquering HA, Majoie CB; MR CLEAN Investigators. Collateral Status on Baseline Computed Tomographic Angiography and Intra-Arterial Treatment Effect in Patients With Proximal Anterior Circulation Stroke. Stroke. 2016;47:768-76.

15. Tan IY, Demchuk AM, Hopyan J, Zhang L, Gladstone D, Wong K, Martin M, Symons SP, Fox AJ, Aviv RI. CT angiography clot burden score and collateral score: correlation with clinical and radiologic outcomes in acute middle cerebral artery infarct. AJNR Am J Neuroradiol. 2009;30:525-31.

16. Naylor J, Churilov L, Rane N, Chen Z, Campbell BCV, Yan B. Reliability and Utility of the Alberta Stroke Program Early Computed Tomography Score in Hyperacute Stroke. J Stroke Cerebrovasc Dis. 2017;26:2547-52.

17. Kucinski T, Majumder A, Knab R, Naumann D, Fiehler J, Väterlein O, Eckert B, Röther J, Zeumer H. Cerebral perfusion impairment correlates with the decrease of CT density in acute ischaemic stroke. Neuroradiology. 2004;46:716-22.

18. Nagel S, Sinha D, Day D, Reith W, Chapot R, Papanagiotou P, Warburton EA, Guyler P, Tysoe S, Fassbender K, Walter S, Essig M, Heidenrich J, Konstas AA, Harrison M, Papadakis M, Greveson E, Joly O, Gerry S, Maguire H, Roffe C, Hampton-Till J, Buchan AM, Grunwald IQ. e-ASPECTS software is non-inferior to neuroradiologists in applying the ASPECT score to computed tomography scans of acute ischemic stroke patients. Int J Stroke. 2017;12:615-22.

19. Kellner E, Urbach H. Machine Outputs Must Be Checked. Clin Neuroradiol. 2021;31:507-8.
20. Goyal M, Ospel JM, Menon B, Almekhlafi M, Jayaraman M, Fiehler J, Psychogios M, Chapot R, van der Lugt A, Liu J, Yang P, Agid R, Hacke W, Walker M, Fischer U, Asdaghi N, McTaggart R, Srivastava P, Nogueira RG, Moret J, Saver JL, Hill MD, Dippel $\mathrm{D}$, Fisher M. Challenging the Ischemic Core Concept in Acute Ischemic Stroke Imaging. Stroke. 2020;51:3147-55. Erratum in: Stroke. 2021;52:e49.

21. Boned S, Padroni M, Rubiera M, Tomasello A, Coscojuela P, Romero N, Muchada M, Rodríguez-Luna D, Flores A, Rodríguez N, Juega J, Pagola J, Alvarez-Sabin J, Molina CA, Ribó M. Admission CT perfusion may overestimate initial infarct core: the ghost infarct core concept. J Neurointerv Surg. 2017;9:66-9.

22. Rotem SH, Mor S, Chen B, Firas S, Elliot S, Ayelet E, Eitan A, Gregory T. Infarct Core Reliability by CT Perfusion is a Time-Dependent Phenomenon. J Neuroimaging. 2020;30:240-5.

23. Powers WJ, Rabinstein AA, Ackerson T, Adeoye OM, Bambakidis NC, Becker K, Biller J, Brown M, Demaerschalk BM, Hoh B, Jauch EC, Kidwell CS, Leslie-Mazwi TM, Ovbiagele B, Scott PA, Sheth KN, Southerland AM, Summers DV, Tirschwell DL. Guidelines for the Early Management of Patients With Acute Ischemic Stroke: 2019 Update to the 2018 Guidelines for the Early Management of Acute Ischemic Stroke: A Guideline for Healthcare Professionals From the American Heart Association/American Stroke Association. Stroke. 2019;50:e344-418. Erratum in: Stroke. 2019;50:e440-1.

24. Seker F, Pfaff J, Nagel S, Vollherbst D, Gerry S, Möhlenbruch MA, Bendszus M, Herweh C. CT Reconstruction Levels Affect Automated and Reader-Based ASPECTS Ratings in Acute Ischemic Stroke. J Neuroimaging. 2019;29:62-4.

25. Neuberger U, Nagel S, Pfaff J, Ringleb PA, Herweh C, Bendszus M, Möhlenbruch MA, Kickingereder P. Impact of slice thickness on clinical utility of automated Alberta Stroke Program Early Computed Tomography Scores. Eur Radiol. 2020;30:3137-45. 